\title{
La vida es un Carnaval. Proyecto de cooperación entre niveles
}

\author{
SARAH TRUJILLO UNDERHILL \\ Southampton District Schools \\ sunderhill@southamptonschools.org \\ ELLEN HATRICK MARTÍN \\ Southampton District Schools \\ emartin@southamptonschools.org \\ LAURA PÉREZ SANCHIS \\ Southampton District Schools \\ lauraperez@educando.es
}

Resumen: El proyecto ha sido llevado a cabo por 87 alumnos de niveles desde A1 hasta B2 del programa bilingüe ISA impartido en el distrito escolar de Southampton, Nueva York. Dicho proyecto interdisciplinar ha surgido de la acción coordinada interniveles entre dos profesoras y la auxiliar de conversación del Ministerio de Educación, Cultura y Deporte de España. En él, los alumnos han aprendido sobre la festividad del Carnaval a través de experiencias reales a través del aprendizaje cooperativo con una variedad de actividades que atienden a las inteligencias múltiples y el respeto a otras culturas a partir del fomento de la educación en valores. El aprendizaje del idioma español se ha desarrollado a partir del enfoque comunicativo orientado a la acción basado en la necesidad del alumno como productores y receptores de la lengua y la cultura hispana.

Palabras clave: Carnaval, aprendizaje cooperativo, inteligencias múltiples, enfoque comunicativo orientado a la acción.

\section{Life is a Carnival. A multi-level collaborative unit of study.}

Abstract: This project has been implemented by 87 students of A1 to B2 levels from within a Bilingual ISA program of the Southampton School District of New York State. The interdisciplinary work of this project is a result of the multilevel collaboration between two teachers and a teaching fellow from the Spanish Ministry of Education and Culture. Students learned about the Carnival festivals through cooperative and actionbased learning with activities that engaged the multiple intelligences, all while experiencing the teaching of values and intercultural respect. The acquisition of the Spanish language has been promoted with a communicative approach and action-based learning where the relevancy of what is being communicated is based on the need of the student who is both the receiver and the user of the Spanish language and its culture.

Key words: Carnival, cooperative learning, multiple intelligences, communicative approach, action-based learning. 


\section{Introducción al proyecto del Programa Bilingüe ISA}

El Distrito público de Southampton se encuentra ubicado en Long Island, Nueva York, Estados Unidos. Desde 2013 este distrito escolar está reconocido como centro ISA (International Spanish Academies); es decir que en su programación se debe incluir una metodología de aprendizaje integrado de contenidos y lengua en español. A la hora de pertenecer a esta red, los centros escolares han firmado un convenio en colaboración con el Ministerio de Educación, Cultura y Deporte español.

El alumnado lo componen niños y adolescentes de entre 5 y 18 años de diferentes niveles socioculturales y económicos. Es por ello que el proceso de enseñanzaaprendizaje del español como lengua extranjera en este tipo de alumnado presenta una serie de características que los profesores de E/LE debemos tener en cuenta a la hora de planificar nuestras sesiones.

En el proyecto La vida es un Carnaval han participado alumnos tanto de SHS como de SIS. Concretamente, han colaborado dos grupos de 25 alumnos de 14 y 15 años de niveles de lengua que oscilan entre el A2 y el B2 del Marco Común Europeo de Referencia (MCER) y dos grupos de 25 alumnos de 10 a 11 años de niveles de lengua que oscilan entre el A1 y el A2 del MCER.

\section{Objetivos del proyecto}

El objetivo principal del proyecto es el aprendizaje sobre la festividad del Carnaval a través de experiencias reales donde tanto los alumnos del Southampton High School (en adelante SHS) como del Southampton Intermediate School (en adelante SIS) pueden contribuir en el proceso de enseñanza-aprendizaje propio y de sus compañeros.

Este objetivo principal se desglosa en los siguientes objetivos específicos:

1. Mejorar el nivel de lengua española y de cultura hispana de los alumnos a través de la máxima inmersión cultural y lingüística.

2. Crear un escenario óptimo de aprendizaje en el que los alumnos forman parte activa como productores y receptores de lengua y cultura hispana.

3. La educación en valores que pone de manifiesto el respeto a otras culturas y la comunicación asertiva sobre el tema a través de la cooperación y la coordinación de alumnos de diferentes edades, niveles de lengua, intereses, culturas y profesores.

\section{Metodología}

El diseño de este proyecto ha seguido dos líneas estructurales que se han desarrollado coordinadamente. No se puede afirmar que sean dos proyectos independientes que se juntan para crear uno más grande, sino que se ha creado un proyecto que acoge actividades que se realizan tanto en el SHS como en el SIS y que funcionan de forma entrelazada para enriquecerse.

Se han tenido en cuenta las metodologías activas y el desarrollo personal y académico de los alumnos. Los procesos evolutivos que presentan los niños y los adolescentes, sus 
ritmos de aprendizaje, sus estados anímicos y sus motivaciones e intereses a la hora de aprender el español deben ser objeto de estudio por parte de los profesores.

Los juegos de nuestros alumnos, sus grupos de amigos, sus culturas, sus tradiciones y sus contextos familiares deben formar parte de la responsabilidad docente a la hora de atender a ello en la programación de actividades que llevamos al aula y que, muchas veces, tienen impacto en la comunidad educativa.

Se programaron una serie de actividades introductorias y conductoras y la tarea final. No obstante, cabe destacar que cuando se llegó a la actividad final, esta misma dio paso a otras tareas posteriores que continuaron el proyecto y lo enriquecieron porque lo propio de un proyecto no solamente es que nazca de la motivación de alumnos y profesores, sino que también crezca y se desarrolle desde esa actitud de querer continuar aprendiendo. Es por ello que la flexibilidad debe tenerse en cuenta al programar un proyecto educativo. A lo largo del proyecto se pueden distinguir las seis partes del EELDRC (enroll, experience, label, demonstrate, revisión, celebrate) (captación, experiencia, etiquetaje, demostración, revisión, celebración) (DePorter, Reardon y Singer-Nourie 2013).

A lo largo de La vida es un Carnaval se ha apostado porque su enfoque estuviera siempre orientado a la acción donde el alumno sintiese la necesidad de comunicarse en español para avanzar en su aprendizaje. Es por ello que el enfoque comunicativo cobra sentido en esta cadena de actividades de manera innata porque «el objetivo fundamental de estos enfoques no es aprender ya gramática, sino conseguir que el alumno pueda comunicarse mejor con la lengua» (Lledó Carreres y Rivera Molina 2010:5).

En este proyecto hemos querido incrementar el interés de nuestros alumnos por el aprendizaje de la lengua y la cultura hispana creando un espacio único formado por ellos mismos. Llevar a las aulas tareas más interesantes y activas donde los protagonistas reales han sido ellos en todo momento ha supuesto a los profesores un giro en la mirada docente ya que cada situación didáctica se debía aprovechar como pretexto desde el cual enlazar enseñanzas, además de «crear atmósferas afectivas de trabajo y gestionar los recursos pedagógicos y materiales» (Lara González 2016:27).

Con todo ello, el proyecto se centra en situar al alumno como foco de su propio aprendizaje, del de sus compañeros de aula y de sus compañeros de distrito escolar y de esta manera, se aporta significatividad y circularidad. En este escenario didáctico, el profesor asume el rol de facilitador, animador del proyecto, guía de experiencias y gestiona tiempos, recursos, eventos y oportunidades dentro del proceso de enseñanzaaprendizaje.

El proyecto ha atendido a la Teoría de las Inteligencias Múltiples de Gardner (2016) al comprender actividades variadas para poder desarrollar y potenciar las inteligencias múltiples de los estudiantes (lingüístico-verbal, naturalista, musical, intrapersonal, interpersonal, lógico-matemática, visual-espacial, cinético-corporal). Así, la variedad de oportunidades de aprendizaje crece desde distintas vías de acceso y desde diversas maneras de empoderar a los alumnos con el aprendizaje.

Estas actividades se han llevado a cabo en agrupamientos variados: de modo individual, parejas, grupos de cuatro alumnos, un grupo de clase entera y un gran grupo con dos clases. 
De esta manera, los alumnos, en grupos reducidos, han trabajado juntos para maximizar su propio aprendizaje y el de sus compañeros (Johnson, Johnson y Holubec 1999). A través de la cooperación, los alumnos han intercambiado aprendizaje y la interacción en español, tanto escrita como oral, ha sido el motor del proyecto.

\section{Descripción del proyecto}

Fase 1:

El proyecto nace con una salida cultural promovida por la Embajada de España en Nueva York y que tiene lugar en el Instituto Cervantes de Nueva York. Esta excursión consistió en un taller sobre cine impartido por el director cinematográfico Iván Cortázar.

A la excursión asistieron los dos grupos de adolescentes de SHS. Al participar ambas clases, la salida se organizó durante dos días consecutivos y en ella se explicó a los alumnos los aspectos relacionados con el mundo del cine tales como qué profesionales están implicados en la producción de una película o cómo se utiliza una cámara profesional.

Seguidamente, los estudiantes prepararon el guion del corto cinematográfico que iban a grabar ese día, el escenario, el maquillaje, el vestuario, ensayaron y, finalmente, rodaron. Fue un día de plena inmersión lingüística, ya que todas las actividades se desarrollaron en español, y también de inmersión cultural ya que tanto el espacio como la comida o las personas formaban parte del mundo hispano.

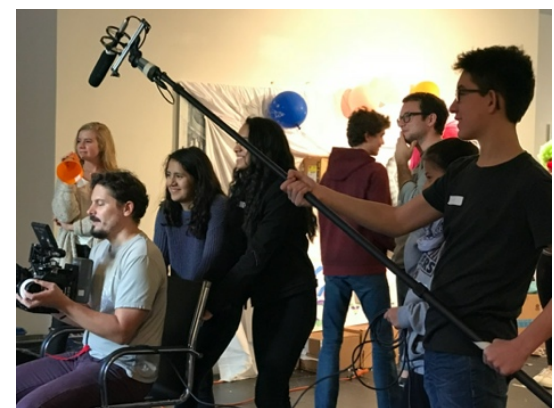

Imagen 1. Alumnos de SHS en el taller cinematográfico en el Instituto Cervantes de Nueva York.

En cuanto a las actividades posteriores a la excursión, en el aula del SHS los alumnos contaron cómo se sintieron, qué fue lo que más les gustó y aquello que podría haber salido mejor. Sus reacciones fueron muy positivas tanto porque se divirtieron como porque aprendieron.

Cuando recibimos el corto de cine ya montado y lo vimos en clase, se generó en el aula un ambiente de agradecimiento por la experiencia vivida y los alumnos escribieron una carta formal a la encargada de educación de la Embajada Española en Nueva York para agradecerle la invitación al taller y otra carta al director cinematográfico para darle las gracias por su trabajo. 


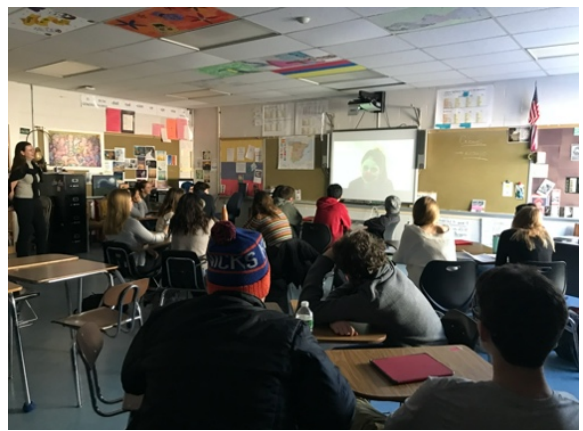

Imagen 2. Visionado de los cortos cinematográficos en clase.

Fase 2:

Para ello, los alumnos sintieron la necesidad de saber cómo se escriben las cartas formales e informales. Mediante un diagrama de Venn, diferenciamos qué aspectos tanto de forma como de uso se emplean en este tipo de escritura. Además, les dimos unos requisitos en una rúbrica diseñada expresamente para ello sobre qué debían cumplir sus cartas a la hora de ser enviadas: la estructura epistolar, que el vocabulario fuera el adecuado para contar y agradecer la experiencia vivida, que en la carta se formularan al menos dos preguntas, que la extensión fuera la adecuada, que se utilizaran todos los tiempos verbales que han estado trabajando recientemente (presente, pretérito imperfecto, pretérito indefinido, pretérito perfecto compuesto y el pretérito pluscuamperfecto), que la adecuación al registro formal fuera correcta, que las frases utilizadas tuvieran diferentes estructuras y que la presencia de conectores fuera notoria (ver anexo 1).

Durante los días que los alumnos estuvieron escribiendo dichas cartas, se reflexionó sobre si la historia del corto que habían protagonizado tenía sentido, sobre los personajes y sobre cómo podría haber sido mejor. Uno de los aspectos que más llamó la atención de nuestros alumnos fue reflexionar sobre cuántas personas quedan involucradas en una producción cinematográfica y, en general, sobre la complejidad de trabajar en el mundo del cine desde distintos puestos de trabajo: cámaras, actores, fotografía, decorados, montaje, guionistas, directores, encargados de las luces, productores y vestuario y su coordinación para obtener un producto final.

Al tratar el tema del vestuario se habló de la necesidad de disfrazarse para realizar un papel y que éste resulte más creíble, de cómo el vestuario es también un medio de comunicación no verbal que nos puede situar en un contexto espacio-temporal y sociológico cultural, que facilita la identificación con el personaje.

Salió a colación el tema de cuándo fue la última vez que nos habíamos disfrazado, por qué a la gente le gusta o no le gusta disfrazarse, cuál había sido su mejor disfraz, y en qué momentos del año la gente se disfraza y salió a la luz el tema del Carnaval y de cómo en muchos países del mundo se celebra esta festividad.

Muchos de los estudiantes conocían el Carnaval y al contar en las clases con diferentes perfiles de alumnos, muchos quisieron compartir cómo se celebra esta fiesta en los países donde tienen familia. En ese momento, como una de las profesoras del SIS iba a empezar a trabajar en sus clases a partir del tópico del Carnaval, nos pusimos en 
contacto con ella, que iba a iniciar el tema del Carnaval inmerso dentro del tópico "Las festividades del Invierno".

Fase 3:

Tras la reflexión sobre cuál era la manera más eficaz de construir aprendizaje sobre el Carnaval juntos y podernos beneficiar todos, llegamos a la conclusión de que los alumnos del SIS prepararían una serie de preguntas sobre esta festividad a través de la rutina de pensamiento: "Qué sé, qué necesito saber y qué he aprendido" (ver anexo 2).

Para ello, los alumnos conocieron las palabras "cuándo", “dónde”, “cuánto", “cómo", "quién", "por qué" en una pregunta, contenido que forma parte del currículo de su asignatura (ver anexo 3). Estas preguntas llegaron a los alumnos del SHS y fueron el eje vertebrador de un proyecto de investigación en el que cada grupo integrado por cuatro alumnos elegiría un país donde se celebrara el Carnaval y destacarían aspectos culturales como su origen, además de dos productos y dos prácticas de esta festividad (ver anexo 4).

Mientras los alumnos de SHS realizaban su proyecto de investigación, los estudiantes de SIS leyeron el libro Rosi y Rafi ;Carnaval!, escrito por la puertorriqueña Lulú Delacre y realizaron una serie de actividades de comprensión lectora y auditiva (ver anexo 5).

Seguidamente, los alumnos dibujaron y colorearon diferentes tipos de vejigantes y la bandera de Puerto Rico. Además, los estudiantes hicieron una búsqueda por Internet sobre la organización del horario de las actividades que se celebran el día o la semana de Carnaval. De esta manera, aprendieron quién era la Reina del Carnaval, el Entierro de la Sardina o el Rey Momo, entre otros.

A continuación, disfrutaron de una clase donde bailaron salsa puertorriqueña y trabajaron la canción de Marc Anthony Vivir mi vida y relacionaron la letra con el tema del Carnaval.

Una vez que los alumnos del SHS acabaron la investigación, la compartieron con sus compañeros del SIS durante una jornada de presentación de proyectos.
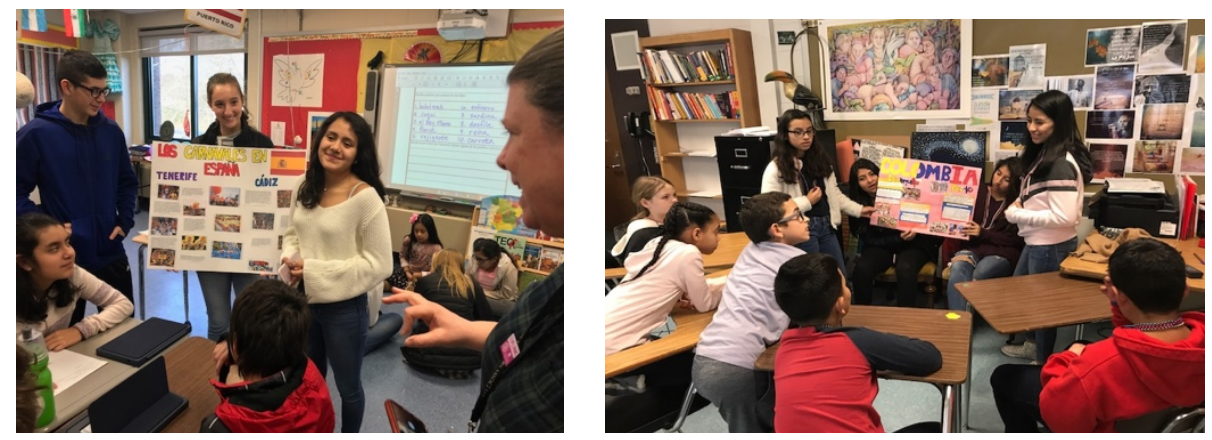

Imágenes 3 y 4. Alumnos del SHS compartiendo con los alumnos del SIS sus investigaciones sobre la celebración del Carnaval en diferentes lugares del mundo.

En el SHS también trabajamos varias canciones sobre el Carnaval como La vida es un Carnaval, de Celia Cruz (ver anexo 6). 
Seguidamente, en el SHS establecimos una conexión en directo con una estudiante del mismo pueblo donde está situado el distrito educativo que actualmente está estudiando en la Universidad de Cádiz. De esta manera, los alumnos pudieron ver en directo la celebración del Carnaval y cómo estaban adornadas las calles.

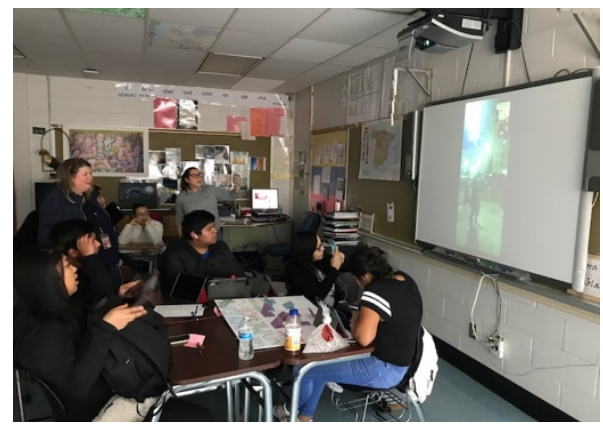

Imagen 5. Conexión en directo desde los carnavales de Cádiz.

En el SIS, los alumnos crearon máscaras vejigantes de manera cooperativa. En parejas, los estudiantes diseñaron y crearon sus propias máscaras con lo que habían aprendido durante los días anteriores tanto en el libro que leyeron como en las explicaciones de sus compañeros del SHS sobre el Carnaval y los disfraces.
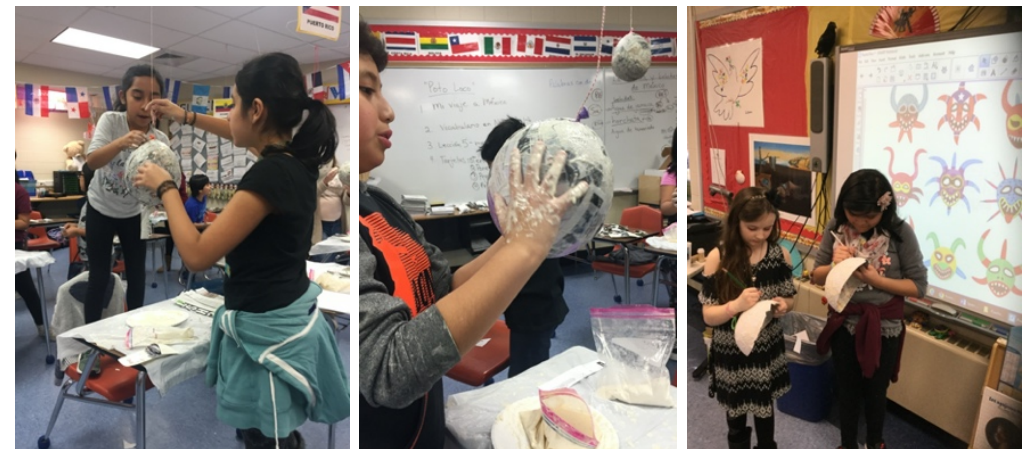

Imágenes 6, 7 y 8. Alumnos del SIS diseñando y creando sus máscaras vejigantes.

Fase 4:

Una vez acabadas las máscaras, los alumnos del SIS desfilaron con ellas puestas hasta llegar al SHS.

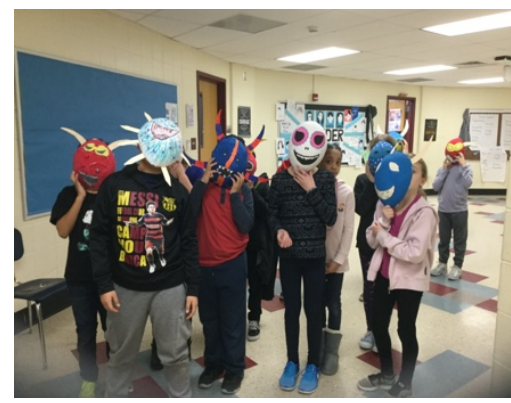

Imagen 9. Desfile de máscaras desde el SIS hasta el SHS. 
Ya juntos los alumnos del SHS y los del SIS, los pequeños explicaron a sus compañeros más mayores cómo las habían hecho. Fueron momentos de aprendizaje compartido donde los estudiantes intercambiaban no solamente conocimiento sino también experiencias personales sobre el Carnaval.
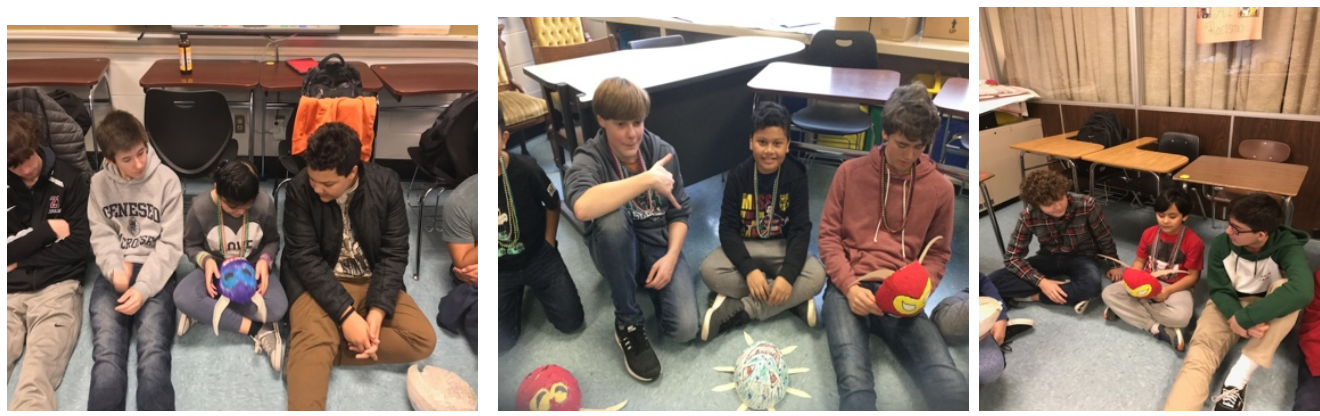

Imágenes 10, 11 y 12. Momentos de compartir reflexiones.

Juntos, vieron los cortos cinematográficos que habían sido el motor de todo este proyecto construido con la escucha activa de los niños, de los adolescentes.

Fase 5:

El proyecto finalizó en el SHS con la lectura de dos tipos de géneros literarios diferentes: un artículo periodístico titulado "El Carnaval en Ponce" que trata las nuevas medidas que se han adoptado este año en dicha celebración y el libro Carnaval en Canarias de Fernando Uría, que nos cuenta la historia de un hombre en el Carnaval de Canarias. Este libro fue trabajado en clase a través de una actividad en la que los alumnos, en parejas, plasmaron cada capítulo en forma de viñeta gráfica.

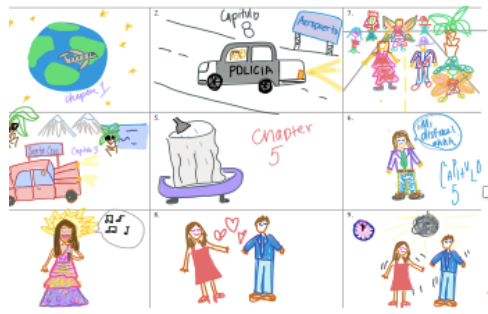

Imagen 13. Actividad de comprensión lectora: viñetas sobre la lectura.

En el SIS, los alumnos acabaron el proyecto completando el organizador gráfico de la rutina de pensamiento que habían empezado al iniciar el proyecto ¿Qué sé? ¿Qué necesito saber? ¿Qué he aprendido? Esta vez contestaron a la última pregunta de manera individual y teniendo en cuenta todo lo que habían experimentado, escuchado, leído y visto durante el proyecto. Finalmente, compartieron sus aprendizajes en gran grupo y recordaron todos lo que sabían y cómo lo habían aprendido. 


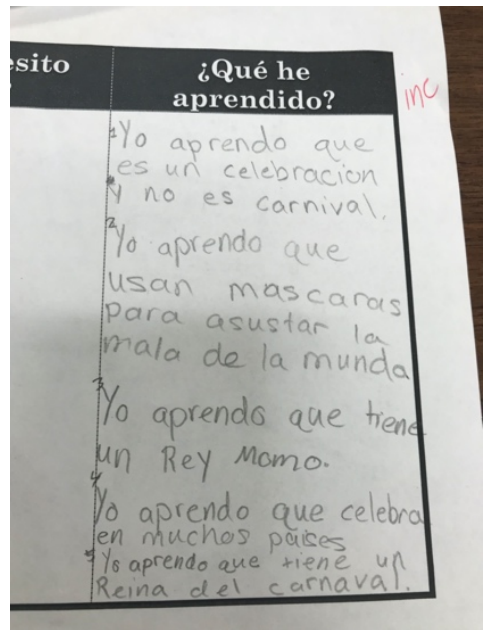

Imagen 14. Muestra de la pregunta final de la rutina de pensamiento ¿Qué sé? ¿Qué necesito saber? ¿Qué he aprendido?

Cabe destacar que el proyecto se ha llevado a cabo coincidiendo con las fechas de Carnaval de 2018, un hecho que ha dotado de realidad al proyecto puesto que en el aula se han podido mostrar vídeos auténticos de desfiles de Carnavales en distintas partes del mundo hispano. La cadena de actividades duró una semana y media con cinco horas semanales de clase.

\section{Resultados del proyecto}

En cuanto a los resultados del proyecto llevado a cabo, la motivación y el entusiasmo por el aprendizaje del español que hemos visto en nuestros alumnos ha sido la mejor retroalimentación del proceso de enseñanza-aprendizaje de español como lengua extranjera en general y, en concreto, del Carnaval.

A lo largo del proyecto, los alumnos han estado más concienciados y pendientes de sus producciones y han aprendido sobre diferentes manifestaciones culturales del mundo hispanohablante a través de una festividad real que se sigue celebrando en muchos países del mundo.

Las competencias del MCER que se han trabajado a lo largo del proyecto son: el conocimiento del mundo y sociocultural, la consciencia intercultural, destrezas y habilidades prácticas e interculturales y la educación en valores además de las competencias lingüísticas, sociolingüísticas y pragmáticas.

Las destrezas desarrolladas con el proyecto La vida es un Carnaval son la expresión oral y escrita, la comprensión auditiva y lectora. Con ello, cabe destacar que la producción tanto escrita como oral de nuestros alumnos ha mejorado notablemente ya que se han proporcionado espacios donde el español no solamente se ha aprendido y utilizado como contenido sino como experiencia real donde tanto estudiantes como profesores han podido usar la lengua con un sentido práctico.

Se han reducido notablemente las faltas de ortografía, han disminuido los errores gramaticales en cuanto a concordancia entre género, número y persona ya que los alumnos estaban más atentos, los signos de puntuación se han utilizado con mayor 
precisión y se ha notado un mejor enfoque en cuanto al registro lingüístico empleado en los diferentes contextos sociales y géneros literarios.

Este proyecto lingüístico y cultural, basado en vivir el español desde la experiencia de conocer diferentes maneras de celebrar el Carnaval, ha enriquecido el bagaje cultural de nuestros alumnos y promueve la inclusión y el empoderamiento de todos nuestros estudiantes que tienen la lengua española como lengua de herencia en Estados Unidos.

Además, el hecho de conectar varios niveles de lengua y de cursos académicos dentro de un mismo distrito escolar ha enriquecido el proyecto, ha favorecido la cooperación entre profesores de E/LE de ambos centros educativos y todo ello ha revertido en el aprendizaje de los alumnos.

Con este proyecto se han logrado aprendizajes más genuinos basados en las experiencias de quienes han contribuido. Es decir, tanto alumnos como profesores han sido partícipes del aprendizaje lingüístico y cultural que promovía el proyecto $\mathrm{y}$, a su vez, también se ha creado, entre todos, un proyecto de carácter social donde la cooperación, la inmersión, el respeto y la comunicación se ha alcanzado, siendo estos ejes vertebradores del programa bilingüe del distrito escolar de Southampton.

\section{Bibliografía}

CONSEJO DE EUROPA (2002). Marco Común de Referencia para las lenguas: aprendizaje, enseñanza, evaluación (MCER). Madrid: Ministerio de Educación, Cultura y Deporte

DELORS, J. y otros (1996). La educación encierra un tesoro. Madrid: Santillana Ediciones UNESCO.

DePorter, Bobby; ReArdon, Mark. y Singer-nOurie, Sara (2013). Quantum teaching. Bandung: Kaifa.

GARDNER, Howard (1983). Frames of Mind. The Theory of Multiple Intelligences. New York: Basic Books Publisher.

Instituto Cervantes (2006). Plan Curricular del Instituto Cervantes. Niveles de referencia para el español. Madrid: Biblioteca Nueva.

Johnson, David, Roger Johnson, Edythe HoluBeC (1999). El aprendizaje Cooperativo en el aula. Buenos Aires: Paidós.

LARA GONZÁLEZ, F. (2016). «La gestión positiva del aula de español para niños». En F. Herrera y N. Sans; Enseñar español a niños y adolescentes (pp. 27-33). Cuadernos de Didáctica. Barcelona: Difusión.

Lledó Carreres, A. y N. Rivera Molina (2010). «Propuestas metodológicas en la adquisición de la competencia en comunicación lingüística: el aprendizaje cooperativo». Alicante: EDUTIC-ADEI, Universidad de Alicante. 
Anexo 1:

\begin{tabular}{|c|c|c|c|c|c|}
\hline \multicolumn{6}{|c|}{ Rúbrica carta formal } \\
\hline & 5 puntos & 4 puntos & 3 puntos & 2 puntos & 1 punto \\
\hline $\begin{array}{l}\text { Informació } \\
\text { n requerida }\end{array}$ & $\begin{array}{c}\text { En la carta } \\
\text { queda } \\
\text { perfectamente } \\
\text { manifiesto el } \\
\text { agradecimiento } \\
\text { por la invitación } \\
\text { y se cuenta la } \\
\text { experiencia } \\
\text { personal }\end{array}$ & $\begin{array}{c}\text { En la carta } \\
\text { queda } \\
\text { manifiesto } \\
\text { pero con fallos } \\
\text { tanto el } \\
\text { agradecimient } \\
\text { o por la } \\
\text { invitación } \\
\text { como la } \\
\text { experiencia } \\
\text { personal }\end{array}$ & $\begin{array}{c}\text { En la carta } \\
\text { queda } \\
\text { manifiesta la } \\
\text { experiencia } \\
\text { personal pero } \\
\text { no el } \\
\text { agradecimiento } \\
\text { por la } \\
\text { invitación }\end{array}$ & $\begin{array}{c}\text { En la carta } \\
\text { queda } \\
\text { manifiesto el } \\
\text { agradecimiento } \\
\text { por la } \\
\text { invitación pero } \\
\text { no la } \\
\text { experiencia } \\
\text { personal }\end{array}$ & $\begin{array}{l}\text { En la carta no } \\
\text { queda } \\
\text { manifiesto el } \\
\text { agradecimiento } \\
\text { por la invitación } \\
\text { ni contada la } \\
\text { experiencia } \\
\text { personal }\end{array}$ \\
\hline $\begin{array}{l}\text { Informació } \\
\text { n requerida }\end{array}$ & $\begin{array}{c}\text { En la carta se } \\
\text { formulan } \\
\text { perfectamente } \\
\text { dos preguntas al } \\
\text { destinatario } \\
\end{array}$ & $\begin{array}{l}\text { En la carta se } \\
\text { formulan dos } \\
\text { preguntas al } \\
\text { destinatario } \\
\text { pero con fallos }\end{array}$ & $\begin{array}{c}\text { En la carta se } \\
\text { formula } \\
\text { perfectamente } \\
\text { una pregunta al } \\
\text { destinatario }\end{array}$ & $\begin{array}{l}\text { En la carta se } \\
\text { formula una } \\
\text { pregunta al } \\
\text { destinatario } \\
\text { pero con fallos } \\
\end{array}$ & $\begin{array}{c}\text { En la carta no se } \\
\text { formulan } \\
\text { preguntas al } \\
\text { destinatario }\end{array}$ \\
\hline $\begin{array}{l}\text { Estructura } \\
\text { epistolar }\end{array}$ & $\begin{array}{c}\text { La carta sigue } \\
\text { perfectamente la } \\
\text { estructura } \\
\text { epistolar de: } \\
\text { encabezamiento } \\
\text {, cuerpo de la } \\
\text { carta y } \\
\text { despedida }\end{array}$ & $\begin{array}{c}\text { En la carta no } \\
\text { aparece la } \\
\text { despedida }\end{array}$ & $\begin{array}{c}\text { En la carta no } \\
\text { aparece el } \\
\text { encabezamient } \\
\text { o }\end{array}$ & $\begin{array}{c}\text { En la carta } \\
\text { solamente } \\
\text { aparece el } \\
\text { encabezamient } \\
\text { o y la } \\
\text { despedida }\end{array}$ & $\begin{array}{c}\text { La carta no } \\
\text { sigue la } \\
\text { estructura } \\
\text { epistolar de: } \\
\text { encabezamiento } \\
\text {, cuerpo de la } \\
\text { carta y } \\
\text { despedida }\end{array}$ \\
\hline $\begin{array}{l}\text { Adecuación } \\
\text { al registro } \\
\text { lingüístico }\end{array}$ & $\begin{array}{l}\text { Uso perfecto y } \\
\text { frecuente del } \\
\text { tratamiento de } \\
\text { usted en la carta }\end{array}$ & $\begin{array}{l}\text { Uso frecuente } \\
\text { pero fallos en } \\
\text { el uso del } \\
\text { tratamiento de } \\
\text { usted en la } \\
\text { carta } \\
\end{array}$ & $\begin{array}{l}\text { Uso poco } \\
\text { frecuente del } \\
\text { tratamiento de } \\
\text { usted en la } \\
\text { carta }\end{array}$ & $\begin{array}{c}\text { Uso perfecto } \\
\text { del tratamiento } \\
\text { de tú en la carta } \\
\text { en lugar del } \\
\text { tratamiento de } \\
\text { usted }\end{array}$ & $\begin{array}{l}\text { Ausencia del } \\
\text { tratamiento de } \\
\text { usted y fallos en } \\
\text { el tratamiento } \\
\text { de tú en la carta }\end{array}$ \\
\hline $\begin{array}{l}\text { Adecuación } \\
\text { al registro } \\
\text { lingüístico }\end{array}$ & $\begin{array}{l}\text { Uso perfecto y } \\
\text { frecuente de } \\
\text { vocabulario } \\
\text { culto y técnico } \\
\text { en la carta }\end{array}$ & $\begin{array}{l}\text { Uso frecuente } \\
\text { pero con fallos } \\
\text { del } \\
\text { vocabulario } \\
\text { culto y técnico } \\
\text { en la carta }\end{array}$ & $\begin{array}{l}\text { Uso poco } \\
\text { frecuente del } \\
\text { vocabulario } \\
\text { culto y técnico } \\
\text { en la carta }\end{array}$ & $\begin{array}{l}\text { Uso perfecto } \\
\text { del vocabulario } \\
\text { estándar y } \\
\text { coloquial en la } \\
\text { carta }\end{array}$ & $\begin{array}{c}\text { Ausencia de } \\
\text { vocabulario } \\
\text { culto y técnico y } \\
\text { fallos en el uso } \\
\text { del vocabulario } \\
\text { estándar y } \\
\text { coloquial en la } \\
\text { carta }\end{array}$ \\
\hline $\begin{array}{l}\text { Tiempos } \\
\text { verbales }\end{array}$ & $\begin{array}{l}\text { Perfecto uso } \\
\text { tanto de la } \\
\text { forma como en } \\
\text { el contexto de } \\
\text { los diferentes } \\
\text { tiempos } \\
\text { verbales } \\
\end{array}$ & $\begin{array}{l}\text { Uso perfecto } \\
\text { en el contexto } \\
\text { pero fallos en } \\
\text { la forma de los } \\
\text { diferentes } \\
\text { tiempos } \\
\text { verbales } \\
\end{array}$ & $\begin{array}{l}\text { Uso perfecto de } \\
\text { la forma pero } \\
\text { fallos en el } \\
\text { contexto de los } \\
\text { diferentes } \\
\text { tiempos } \\
\text { verbales }\end{array}$ & $\begin{array}{c}\text { Fallos tanto en } \\
\text { la forma como } \\
\text { en el contexto } \\
\text { de los } \\
\text { diferentes } \\
\text { tiempos } \\
\text { verbales } \\
\end{array}$ & $\begin{array}{l}\text { Ausencia de } \\
\text { verbos } \\
\text { conjugados en } \\
\text { los diferentes } \\
\text { tiempos } \\
\text { verbales }\end{array}$ \\
\hline Estructura & Uso perfecto de & Uso de frases & Uso de frases & Uso de frases & Todas las frases \\
\hline
\end{tabular}




\begin{tabular}{|c|c|c|c|c|c|}
\hline de las frases & $\begin{array}{c}\text { frases cortas, } \\
\text { largas y hay } \\
\text { más de un } \\
\text { conector por } \\
\text { párrafo }\end{array}$ & $\begin{array}{c}\text { cortas, largas y } \\
\text { hay un } \\
\text { conector por } \\
\text { párrafo }\end{array}$ & $\begin{array}{c}\text { cortas, largas } \\
\text { pero no hay un } \\
\text { conector por } \\
\text { párrafo }\end{array}$ & $\begin{array}{c}\text { cortas pero no } \\
\text { largas y hay un } \\
\text { conector por } \\
\text { párrafo }\end{array}$ & $\begin{array}{c}\text { son cortas y no } \\
\text { hay ningún } \\
\text { conector }\end{array}$ \\
\hline
\end{tabular}

Anexo 2:

RUTINA DE PENSAMIENTO:

\begin{tabular}{|l|l|l|}
\hline ¿Qué sé? & ¿Qué necesito saber? & ¿Qué he aprendido? \\
\hline & & \\
& & \\
& & \\
\hline
\end{tabular}

Anexo 3:

PREGUNTAS MOTIVADORAS:

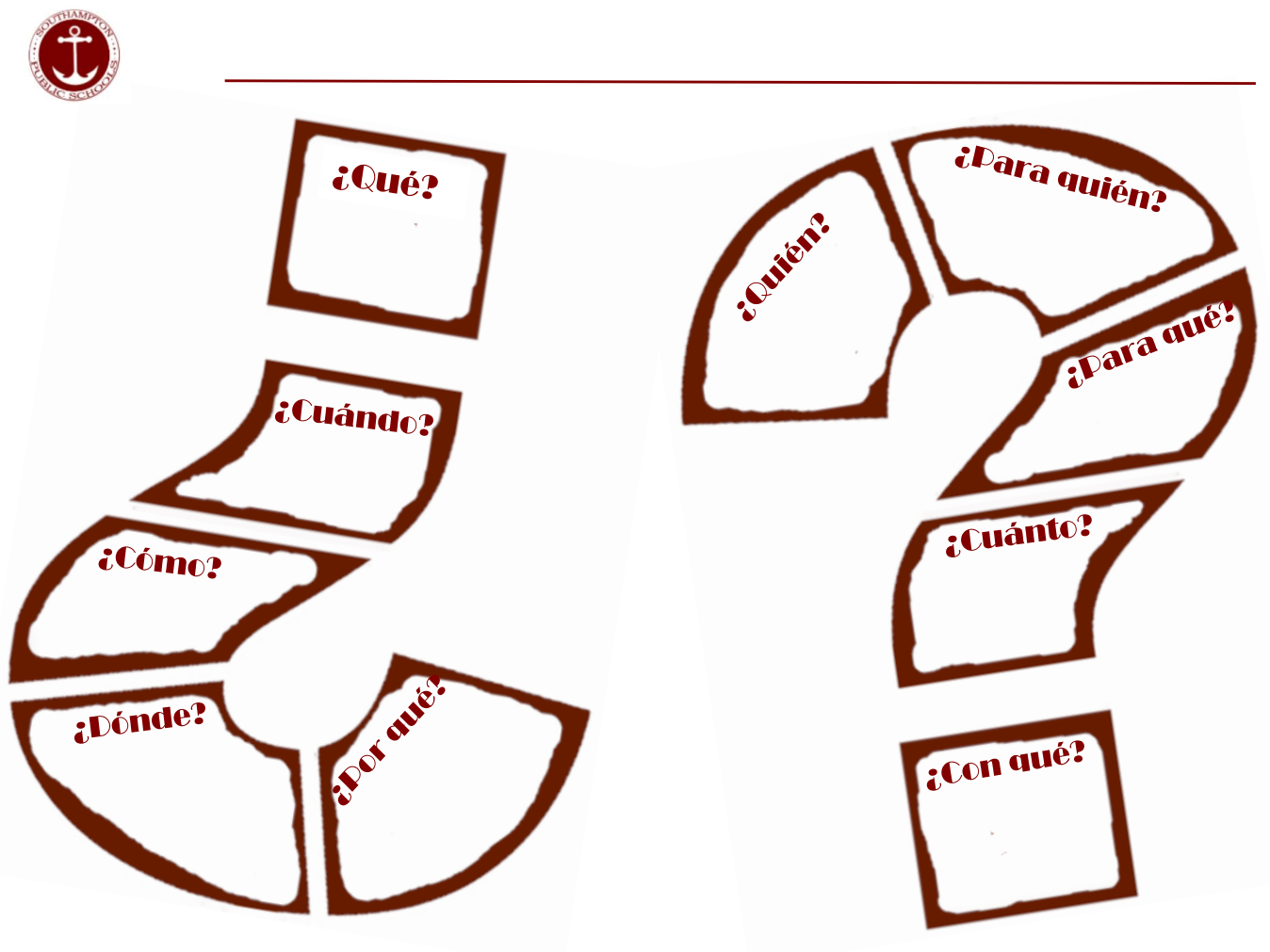

Ellen Martín y Laura Pérez Sanchis 
Anexo 4:

\begin{tabular}{|c|c|c|c|c|c|}
\hline \multicolumn{6}{|c|}{ Rúbrica sobre la investigación del Carnaval } \\
\hline & 5 puntos & 4 puntos & 3 puntos & 2 puntos & 1 punto \\
\hline Tema & $\begin{array}{c}\text { La } \\
\text { investigación } \\
\text { trata el tema del } \\
\text { Carnaval } \\
\text { perfectamente }\end{array}$ & $\begin{array}{c}\text { La } \\
\text { investigación } \\
\text { trata el tema } \\
\text { del Carnaval } \\
\text { pero se desvía } \\
\text { en algún punto }\end{array}$ & $\begin{array}{c}\text { La } \\
\text { investigación } \\
\text { trata diferentes } \\
\text { temas }\end{array}$ & $\begin{array}{c}\text { La } \\
\text { investigación } \\
\text { nombra } \\
\text { solamente el } \\
\text { tema del } \\
\text { Carnaval } \\
\end{array}$ & $\begin{array}{l}\text { El tema del } \\
\text { Carnaval no es } \\
\text { tratado en la } \\
\text { investigación }\end{array}$ \\
\hline $\begin{array}{l}\text { Variedad de } \\
\text { fuentes }\end{array}$ & $\begin{array}{c}\text { Se han } \\
\text { consultado más } \\
\text { de tres fuentes }\end{array}$ & $\begin{array}{c}\text { Se han } \\
\text { consultado tres } \\
\text { fuentes }\end{array}$ & $\begin{array}{c}\text { Se han } \\
\text { consultado dos } \\
\text { fuentes } \\
\end{array}$ & $\begin{array}{c}\text { Se ha } \\
\text { consultado una } \\
\text { fuente }\end{array}$ & $\begin{array}{c}\text { No se han } \\
\text { consultado } \\
\text { ninguna fuente } \\
\end{array}$ \\
\hline $\begin{array}{c}\text { Aspectos } \\
\text { lingüísticos }\end{array}$ & $\begin{array}{l}\text { La acentuación, } \\
\text { la concordancia, } \\
\text { el vocabulario y } \\
\text { la puntuación } \\
\text { son perfectas }\end{array}$ & $\begin{array}{c}\text { La } \\
\text { concordancia, } \\
\text { la acentuación } \\
\text { y el } \\
\text { vocabulario } \\
\text { son perfectos, } \\
\text { pero hay fallos } \\
\text { en la } \\
\text { puntuación }\end{array}$ & $\begin{array}{c}\text { La } \\
\text { concordancia y } \\
\text { la acentuación } \\
\text { son perfectos, } \\
\text { pero hay fallos } \\
\text { en el } \\
\text { vocabulario y } \\
\text { la puntuación }\end{array}$ & $\begin{array}{l}\text { La } \\
\text { concordancia } \\
\text { es perfecta, } \\
\text { pero hay fallos } \\
\text { en la } \\
\text { acentuación, el } \\
\text { vocabulario y } \\
\text { la puntuación }\end{array}$ & $\begin{array}{c}\text { Hay fallos tanto } \\
\text { en la } \\
\text { concordancia } \\
\text { como en la } \\
\text { acentuación, en } \\
\text { el vocabulario y } \\
\text { en la puntuación }\end{array}$ \\
\hline $\begin{array}{l}\text { Contestar a } \\
\text { las } \\
\text { preguntas } \\
\text { formuladas } \\
\text { por los } \\
\text { alumnos del } \\
\text { SIS } \\
\end{array}$ & $\begin{array}{l}\text { Se responde a } \\
\text { todas las } \\
\text { preguntas } \\
\text { formuladas }\end{array}$ & $\begin{array}{l}\text { Solamente se } \\
\text { responde a tres } \\
\text { preguntas } \\
\text { formuladas }\end{array}$ & $\begin{array}{l}\text { Solamente se } \\
\text { responde a dos } \\
\text { de las } \\
\text { preguntas } \\
\text { formuladas }\end{array}$ & $\begin{array}{l}\text { Solamente se } \\
\text { responde a una } \\
\text { de las } \\
\text { preguntas } \\
\text { formuladas }\end{array}$ & $\begin{array}{c}\text { No se responde } \\
\text { a ninguna de las } \\
\text { preguntas } \\
\text { formuladas }\end{array}$ \\
\hline $\begin{array}{l}\text { Orígenes } \\
\text { del } \\
\text { Carnaval en } \\
\text { este país }\end{array}$ & $\begin{array}{l}\text { Los orígenes } \\
\text { quedan bien } \\
\text { plasmados en la } \\
\text { investigación }\end{array}$ & $\begin{array}{l}\text { Los orígenes } \\
\text { quedan bien } \\
\text { plasmados en } \\
\text { la } \\
\text { investigación } \\
\text { pero con fallos } \\
\end{array}$ & $\begin{array}{l}\text { Los orígenes } \\
\text { quedan } \\
\text { plasmados en } \\
\text { la investigación } \\
\text { pero de manera } \\
\text { breve }\end{array}$ & $\begin{array}{l}\text { El tema de los } \\
\text { orígenes } \\
\text { solamente se } \\
\text { menciona pero } \\
\text { no se explica }\end{array}$ & $\begin{array}{l}\text { No se responde } \\
\text { el tema de los } \\
\text { orígenes }\end{array}$ \\
\hline Producto & $\begin{array}{l}\text { Descripción, } \\
\text { ubicación y } \\
\text { comparación } \\
\text { con otros } \\
\text { productos del } \\
\text { mismo país }\end{array}$ & $\begin{array}{l}\text { Descripción y } \\
\text { comparación } \\
\text { con otros } \\
\text { productos del } \\
\text { mismo país } \\
\text { pero no } \\
\text { ubicación } \\
\end{array}$ & $\begin{array}{l}\text { Comparación } \\
\text { con otros } \\
\text { productos del } \\
\text { mismo país } \\
\text { pero no } \\
\text { descripción ni } \\
\text { ubicación } \\
\end{array}$ & $\begin{array}{l}\text { Descripción } \\
\text { pero no } \\
\text { ubicación ni } \\
\text { comparación } \\
\text { con otros } \\
\text { productos del } \\
\text { mismo país }\end{array}$ & $\begin{array}{l}\text { Ni descripción, } \\
\text { ni ubicación, ni } \\
\text { comparación } \\
\text { del producto } \\
\text { con otros del } \\
\text { mismo país }\end{array}$ \\
\hline Práctica & $\begin{array}{l}\text { La práctica } \\
\text { queda bien } \\
\text { plasmada en la } \\
\text { investigación }\end{array}$ & $\begin{array}{l}\text { La práctica } \\
\text { queda bien } \\
\text { plasmada en la } \\
\text { investigación } \\
\text { pero con fallos }\end{array}$ & $\begin{array}{c}\text { La práctica } \\
\text { queda } \\
\text { plasmada en la } \\
\text { investigación } \\
\text { pero de manera } \\
\text { breve }\end{array}$ & $\begin{array}{l}\text { La práctica } \\
\text { solamente se } \\
\text { menciona pero } \\
\text { no se explica }\end{array}$ & $\begin{array}{c}\text { No se menciona } \\
\text { ninguna } \\
\text { práctica }\end{array}$ \\
\hline $\begin{array}{l}\text { Contraste de } \\
\text { diferentes }\end{array}$ & $\begin{array}{l}\text { Se contrastan } \\
\text { perfectamente }\end{array}$ & $\begin{array}{l}\text { Se contrastan } \\
\text { dos zonas de }\end{array}$ & $\begin{array}{c}\text { Se contrastan } \\
\text { dos zonas de un }\end{array}$ & $\begin{array}{c}\text { Se contrastan } \\
\text { dos zonas de un }\end{array}$ & $\begin{array}{l}\text { Solamente se } \\
\text { habla de una }\end{array}$ \\
\hline
\end{tabular}




\begin{tabular}{|c|c|c|c|c|c|}
\hline $\begin{array}{c}\text { zonas de } \\
\text { cada país }\end{array}$ & $\begin{array}{c}\text { más de dos } \\
\text { zonas de un } \\
\text { mismo país }\end{array}$ & un mismo país & mismo país & $\begin{array}{c}\text { mismo país } \\
\text { pero con fallos }\end{array}$ & zona del país \\
\hline $\begin{array}{c}\text { Formato: } \\
\text { diapositivas, } \\
\text { vídeo o } \\
\text { póster }\end{array}$ & $\begin{array}{c}\text { El formato } \\
\text { elegido es uno } \\
\text { de los } \\
\text { propuestos y se } \\
\text { cuida la } \\
\text { presentación: } \\
\text { atractivo, } \\
\text { visual, didáctico } \\
\text { para los } \\
\text { alumnos del SIS }\end{array}$ & $\begin{array}{c}\text { El formato } \\
\text { elegido es uno } \\
\text { de los } \\
\text { propuestos } \\
\text { pero no es } \\
\text { didáctico para } \\
\text { los alumnos } \\
\text { del SIS }\end{array}$ & $\begin{array}{c}\text { El formato } \\
\text { elegido es uno } \\
\text { de los } \\
\text { propuesto, es } \\
\text { didáctico pero } \\
\text { no es atractivo } \\
\text { ni visual }\end{array}$ & $\begin{array}{c}\text { El formato } \\
\text { elegido es uno } \\
\text { de los } \\
\text { propuestos pero } \\
\text { no se cuida la } \\
\text { presentación: ni } \\
\text { es atractivo ni } \\
\text { es didáctico }\end{array}$ & $\begin{array}{c}\text { No se presenta } \\
\text { en ninguno de } \\
\text { los formatos } \\
\text { propuestos }\end{array}$ \\
\hline
\end{tabular}

Anexo 5:

\begin{tabular}{|l|}
\hline \multicolumn{2}{|c|}{$\begin{array}{c}\text { Comprensión lectora: } \\
\text { Rafi y Rosi ¡Carnaval! }\end{array}$} \\
\hline Nombre del lector: \\
\hline Nombre de la escritora: \\
\hline ¿Quiénes son los personajes principales? \\
\hline Dibuja tu personaje favorito: \\
\hline ¿Dónde ocurre la historia? \\
\hline ¿El libro tiene muchas imágenes o pocas imágenes? \\
\hline La lectura es fácil \\
\hline Lo que más me gusta de este libro es:
\end{tabular}


Anexo 6

\section{La vida es un Carnaval. Celia Cruz}

Todo aquel que piense que la vida es

Tiene que que no es as!

Que la vida es una hay que vivirla

Todo aquel que piense que está y que está mal

Tiene que saber que no es asi

Que en la vida no hay nadie solo, siempre hay

Ay, no hay que

Que la vida es un y es más bello vivir

Oh oh oh ay no hay que

Que la vida es un carnaval y las se van cantando

Oh oh oh ay no hay que llorar

Que la vida es un carnaval y es más vivir cantando

Oh oh oh ay no hay que llorar

Que la es un carnaval y las penas se van

Todo aquel que piense que la vida siempre es

Tiene que saber que no es asi

Que tan solo hay $y$ todo pasa

Todo aquel que piense que esto va a cambiar

Tiene que saber que no es así 
Que al mal tiempo y todo cambia.

Carnaval, es para

No hay que llorar, para

Carnaval, para disfrutar

Hay que vivir cantando

Carnaval, la vida es un carnaval

No hay que llorar, todos podemos

Carnaval, ay señores

Hay que vivir cantando

Carnaval, todo aquel que piense

Que la vida es cruel

Carnaval,

Hay que vivir cantando, Dios está con él.

Para aquellos que tanto

Para aquellos que solo

Para aquellos que usan las

Para aquellos que

Para aquellos que

Para aquellos que

Para aquellos que nos maltratan

Para aquellos que nos 